\title{
Evaluating the Linkage Between Employee Training Programmes and Prosocial Organizational Behavior*
}

\author{
Hassan R. H. Elkhdra , Aysun Kanbur ${ }^{b}$
}

Abstract: This study has been conducted to evaluate the effect of employee training programmes on prosocial organizational behaviors. Empirical research was performed with the employees of Arabian Gulf Oil Company (AGOCO). Questionnaire technique was used for gathering the data. At this juncture, accepted scales in the literature related to variables were utilized. Prosocial organizational behaviors were identified in the literature as prosocial organizational behavior, role-prescribed prosocial behavior, and prosocial individual behavior while employee training programmes were examined in terms of motivation for training, benefits of training, and support for training. Variables of this study were accepted using these classifications and hypotheses were tested through correlation and regression analyses. All the hypotheses were supported and the findings that have been obtained provide that motivation for training, benefits of training, and support for training have a significantly positive effect on prosocial organizational behaviors of employees working at Libyan oil sector and specifically employees of AGOCO. The findings of the study will be beneficial for the Libyan oil sector and other sectors to improve their strategy regarding employee training programmes and prosocial organizational behaviors.

\author{
Keywords: Employee Training \\ Programmes, Motivation for \\ Training, Benefits of Training, \\ Support for Training, \\ Prosocial Organizational \\ Behavior
}

JEL: M10, M19, M53

\section{Introduction}

Training has gained popularity as a key function of human resources management like others such as orientation, job analysis, compensation, performance appraisal, welfare activities, and employee relations. Implementing successful human resource management can only be gained through regular training. Studies on training seem to confirm that it is a very significant investment as it improves knowledge, updates skills, improves employees' attitudes, and creates competencies for the longevity and sustainability of the organization. Also, training investments help enhance organizational performance by increasing intellectual capital (Barney, 2001; Noe, 2010). Companies invest in the training of employees for value addition (Huselid, 1995; Shen, 2005). Training results in augmenting employee skills and organizational competitive edge (Nikandrou, Brinia \& Bereri, 2009). Management needs to give its workforce the required vision and ability to perform (Jehanzeb \& Bashir, 2013).

Employees of an organization intentionally show prosocial organizational behaviors (POB) for benefiting their organization, just one of its departments, some specific individual, or a group; therefore,

a Asst. Prof., PhD., The High Institute for Engineering Professions, Almajurie, Benghazi, Libya, hass_elkader@yahoo.com (ORCID ID: 0000-0002-3345-1559)

b Assoc. Prof., PhD., Kastamonu University, Economics and Administrative Sciences Faculty, Department of Business Administration, Kastamonu, Turkiye, akanbur@kastamonu.edu.tr (ORCID ID: 0000- 0002-5950-0865) 
they are useful within an organization whether voluntarily or involuntarily (Brief \& Motowidlo, 1986; Organ \& Konovsky, 1989). Many organizational scientists are paying attention to this subject because of its significance for organizational development and they are trying to understand prosocial responses by focusing on empirical evidence (O'Reilly \& Chatman, 1986).

It is thought that $\mathrm{POB}$ increases through the provision of appropriate training programmes and benefits, and also through communication and clarifying the message regarding the organization's vision and goals, employee development support, etc. Therefore, it is important to reveal the effect of employee training programmes on $\mathrm{POB}$. Examining these variables helps to gain knowledge about employee training programmes and POBs. In this context, this study aims to enhance understanding of how employee training programmes affect prosocial organizational behavior.

\section{Theoretical Framework}

\subsection{Employee Training Programmes}

Training helps organizations to improve quality and to give their employees an idea about skillset needs to make their jobs effectively conducted. It also helps an organization to compete successfully. Training makes an individual or group of people more efficient, productive, or useful to an organization (Bature, Friday \& Mustapha, 2013; Tunio, Channa \& Pathan, 2016). The Manpower Services Commission (1981) defines training as "a planned process to modify attitude, knowledge or skill behavior through learning experience to achieve performance in an activity or range of activities and its purpose, in a work situation is to develop the abilities of the individual and to satisfy the current and future needs of the organization" (Egan, Raats, Grubb, Eves, Lumbers, Dean \& Adams, 2007). Training attempts to modify and direct one's abilities toward a particular activity (Reid \& Barrington, 2001). Within organizations, the investment in training is intended to result in improved performance of both the learners and the organization. All this throws light on the need for well-planned training programmes specifically tailored for better and higher productivity.

To yield benefits both for individuals and organizations, training programmes should be properly conducted systematically. Therefore, to have a general understanding of training programmes, it might be useful to highlight the stages of training. According to Bramley (1991), there are five stages in process of a training programme. They are generally known as a systematic training cycle. The process is described as systematic because it emphasizes logical and sequential planning and action. The systematic training cycle is the interaction between identification of training needs, setting of objectives, selection of methods, running the training, and evaluative feedback loops. Training is the joint responsibility of the senior management, line management, training department, and individuals. In other words, everyone in the organization has a part to play in training programmes and this is a collective responsibility (Reid \& Barrington, 2001).

Organizations offer many training forms, which managers identify as important for the profitability of the organizations. Most commonly used approaches to training by organizations include on-the-job training methods and off-the-job training methods (Gomez-Mejia, Balkin \& Cardy, 2012; Molla Belay, 2016). On-the-job training form of training is very widely used to provide the trainees with the necessary skills techniques by practical experience at different levels over a period (Armstrong, 1999). Off-the-job training is also beneficial in the sense that employees get training for longer periods, and besides, getting training in a classroom can make the educational process easier and formal without interruptions, which typically takes place in an off-the-job training environment (Gomez-Mejia, Balkin \& Cardy, 2012).

\subsection{Prosocial Organizational Behaviors}

Prosocial attitudes/behaviors are good citizenship or extra-role attitudes for workplaces. These are socially desirable, correct, or friendly behaviors. Everyone believes that as citizens of a society, everyone should behave in a prosocial manner for broader prospects and stability in the society (Zellars, Tepper \& Duffy, 2002). McDougall (1908) first discussed prosocial behavior, which sparked debate in the field and academic circles (Fatkin, 2015). Later, Werner (1994) claimed that "tender emotions" are responsible for 
prosocial behavior and those tender emotions are the products of parental behaviors. Since research could find triggers, which could help improve the employees' behavior, the topic gained researchers' attention.

Prosocial behavior lies in three categories in terms of research purposes. It can be micro, macro, or meso. Micro-analysis analyzes prosocial predispositions in employee behaviors and covers differences between individual behaviors in the given context. Meso-analysis is about helper-recipient coordination, relations, and interactions. Macro-analysis explains how groups, organizations, and multiple stakeholders interact with each other. This type has significance because the current age is the age of incorporates, consortiums, and globalization (Piliavin \& Charng 1990; Dovidio \& Penner 2001). Prosocial behaviors depend on many factors and people exhibit them on many levels such as individual, group, or organizational levels (Penner, Dovidio, Piliavin \& Schroeder, 2005).

Early recognition of prosocial behavior begins with inferences by Katz (1964). He investigated human motivation within organizations, identified three behaviors needed for organizational functions: (1) convince employees to continue with their jobs for long; (2) assure that employees do their jobs in a trustworthy way; and (3) they should be ready to do extra-role tasks. Katz is speaking of those actions included in the present definition of prosocial behavior. According to classical concepts presented by Katz and Kahn (1966), the behaviors of some employees are beyond the roles they play in their organizations. They claimed that these unstructured attitudes (beyond job description) are somehow necessary for any organization's survival and competitiveness. In a continuation of the study of prosocial behavior in an organizational context, Organ (1977) investigated the hypothesis that satisfaction causes performance. Bateman and Organ (1983) continued the investigation of the satisfaction/performance linkage and wrote about "citizenship" behaviors. Then, Smith, Organ, and Near (1983) investigated the nature and antecedents of organizational citizenship behaviors. In the continued studies of prosocial behavior in an organizational context, several labels have emerged. The label of organizational citizenship behavior was introduced, as mentioned. Other labels of helping behaviors in organizations (Kaplan \& Cowen, 1981), and POB (Brief \& Motowidlo, 1986) have been used to describe prosocial acts. Brief and Motowidlo (1986) wrote about prosocial organizational behaviors, and described thirteen kinds of these behaviors; providing assistance to coworkers for resolving on-the-job problems or tasks, helping out colleagues to resolve personal issues, exhibiting lenient attitude after taking decisions on matters pertaining to personnel/human resources issues, giving smooth and consistent services or product supplies in hassle-free way to the customers, giving product and service supplies to customers through organizationally inconsistent processes, providing support to consumers and making them deal with their personal issues, which are not linked with the organization's services or products, showing full compliance with employing organization's policies, values, and rules, giving suggestions to make positive changes in the procedures, and administrative/organizational system, raising voice against inappropriate orders, processes and policies, investing extra or more-than-necessary effort, providing services as a volunteer to accomplish additional/extra tasks, managing to prolong stay in the organization in spite of hardships and positively representing the employing organization before outsiders. Brief and Motowidlo (1986) suggest the research of POBin four areas: the underlying dimensions of prosocial behavior, what conditions influence prosocial behaviors, how can managers cultivate an increase in prosocial organizational behaviors, and what are correlates of prosocial organizational behavior.

$\mathrm{POB}$ can be defined as a "behavior, which an organization's member exhibits while interacting and increasing the welfare of a person, group or organization during an interaction as a part of his or her role", and he clarified that prosocial contributions are not essentially 'duties' of a person as an employee (Lee, 2001). Moving further with efforts to explain the dynamics of prosocial behavior, Brief and Motowidlo (1986) suggested that there were three axes of prosocial behaviors. They claimed that these functions can be either functional or dysfunctional, and they may be a regular duty or an extra one. At last, they pointed out that prosocial actions may be for the welfare of individuals or groups. George and Brief (1992) pointed out that three of the prosocial concepts are different as compared to others on psycho-behavioral grounds. Both citizenship behaviors and organizational spontaneity are functional behaviors but the prosocial behaviors comprise of functional and dysfunctional behaviors, for example, flexibility after taking a decision is a dysfunctional behavior but sometimes, it may be quite helpful. McNeely and Meglino (1994) argued that 
prosocial behaviors have particular beneficiaries and organizations are mostly their beneficiaries. Prosocial behaviors give an advantage to the organization but those behaviors benefit some individuals as well. Researches establish them as major beneficiaries.

Many researchers conducted researches to understand different aspects of prosocial behaviors and their relevant components. Brief and Motowidlo (1986) conducted very important researches on prosocial behaviors and their work is considered a classic work on the subject. They said that prosocial behavior is generally performed by an employee for the welfare of other people, departments, or organizations. Organ and Konovsky (1989) pointed out that prosocial behaviors are a social and economic mix of relations within an organization. Staw (1984) mentioned that some prosocial behaviors are targeted to develop the whole organization. Brief and Motowidlo (1986) believed that understanding prosocial behaviors might lead to discoveries, which can result in finding strategies to assure organizational development.

Prosocial behaviors are considered as advantageous and helpful behaviors not only for the organizations but for individuals as well. These behaviors can be termed as "valuable contributors" to both sides (individuals or the organization) (Boundenghan, Desrumaux, Leoni \& Nicolas, 2012). It has long been recognized that prosocial actions are beneficial for organizations. Their positive effects have been extensively emphasized in the available literature (Bolino \& Grant, 2016). Prosocial behavior not only helps the receiving side but the giving side as well, and besides, its benefits are multiple and multi-faceted (Bülbül, 2014). In the context of the social exchange mechanism, researchers have proposed two further kinds of explanations, which clarify the advantages of prosocial behaviors. According to the motivational perspective, when the actions of employees benefit others, they feel a sense of self-worth and also feel purpose and meaning in their lives that motivates them to work harder, better/smarter, or for a longer duration of time (Elliott, Kao \& Grant, 2004). It is a reality that the times some employees invest while extending support to others can make them address their issues. Researchers believe that the employees, who devote their time to solving others' problems, develop extra and critical skills while doing so (McGrath, Vance \& Gray, 2003; Booth, Park \& Glomb, 2009; Grant, 2012). Prosocial actions support employees' mutual relations and repute (Salamon \& Deutsch, 2006; Casciaro \& Lobo, 2008; Kim \& Glomb, 2010).

\subsection{Relationship Between the Variables of the Research}

Organizational behavior focuses on the ways the employees behave in their organizations (Hendry, 2012). A research field that takes attention in organizational behavior discipline is prosocial organizational behaviors. Thus, it becomes important to understand the relationship between employee training programmes and prosocial organizational behavior. Training is an organized procedure in organizations. Employees must be given proper training so that they can enhance their skills and show their worth by delivering the expected performance for their organizations. Employees should be trained in a way by which they can adjust to all the changes in the organizational environment. All the required knowledge and skills can be obtained by the employees using going through proper training (Hendry, 2012). On the other hand, POBs are considered to be very important behaviors, which are elemental for the success of the organizations. POBs have a huge implication on the overall performance of the organizations (Hazzi \& Maldaon, 2012). Organizations will be able to survive properly if they perform prosocial organizational behaviors. POBs are generally enacted by the individuals of an organization when s/he carries out his or her functions for the organization by communicating with his/her colleagues. Different kinds of POBs can be highlighted in this context.

In the interpersonal communication literature, being as a well-established mechanism, the Theory of Norm of Reciprocity, which reflects the tendency to return to goodness taken from others, draws attention (Lee \& Liang, 2015). Rabin (1993) explains reciprocity by being polite (rude) to people who are polite (rude) to them (Lopez-Perez, 2009). This theory can be evaluated as explanatory for the link between employee training programmes and employees' orientation towards prosocial organizational behaviors. Similarly, Social Exchange Theory can be thought of in this context. When an organization provides opportunities for promotion, development, and appreciation for its employees, it is argued that the organization initiates a social exchange relationship that employees feel obliged to respond socially with a more positive attitude 
(Cicekli \& Kabasakal, 2015). Thus, employee training programmes and POBs can be considered as the elements of a social exchange relation among the organization and the employee. Expectation Theory is also explanatory for this link. When employees' expectations are met with training, the gains that the employee will provide from training can turn into outputs for displaying prosocial behaviors. The provision of motivators such as training can motivate employees' voluntary efforts (Frenkel \& Bednall, 2016). Namely, future reward expectations can become the reason for prosocial organizational behavior.

It has been a matter of discussion as employee training programmes could lead to the success of the organization from all directions (Hazzi \& Maldaon, 2012). If the employee-directed POBs are not properly performed, the employees will not learn the ways they should conduct with their colleagues and most importantly with their clients (Armstrong \& Taylor, 2014). The organization can function smoothly only if the employees are well-organized and behave properly according to the ethical values of the organization. Experts should always behave well and cooperate with the workers. These particular behaviors are very necessary for the survival of the organizations (Hazzi \& Maldaon, 2012). These things are also taught in the training process. This is considered to be one of the most interesting responsibilities for human resource managers. Human resource managers should incur a sense of responsibility in the employees through proper training (Armstrong \& Taylor, 2014).

It is believed that taking up the additional roles or the extra roles is a part of the POBs and the employees should be trained by the human resource managers for that. All these things should be directed towards meeting the organizational goals and achieving organizational success. Ultimately, it can be expressed that organizations which have prosocial behaviors are very inspiring for achieving organizational success. It can be accepted as the responsibility of the human resource managers to make the employees efficient enough to comply with the needs of the organizations.

\section{Methodology}

\subsection{Aim}

The aim of this research is to identify the effect of employee training programmes on POBs of employees in the Libyan oil sector, specifically in the Arabian Gulf Oil Company (AGOCO). More in detail to understand this link, it is thought that motivation for training, benefits of training, and support for training have a role in different aspects of prosocial organizational behaviors. It is also aimed to enrich the current literature related to training programmes in organizations and POBs through the findings of the research.

\subsection{Research Model}

The research model of the study was established depending on the main purpose of the research that emphasizes the effect of employee training on POBs. Variables of the model and their subdimensions were accepted in the research model in the context of the literature related to the main concepts of the study.

Figure 1. Research Model
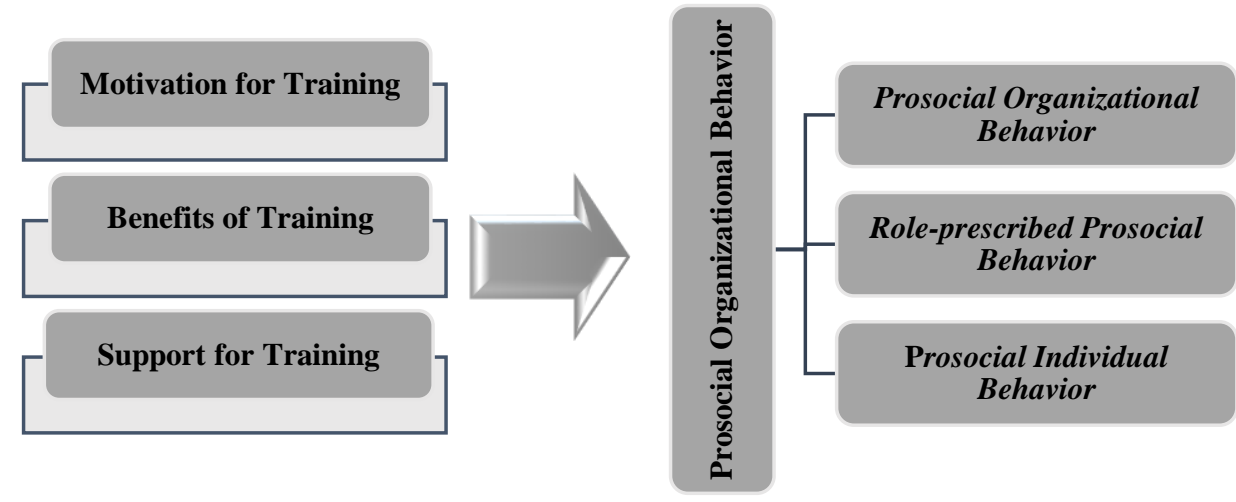
Dependent and independent variables were shown in the research model. Motivation for Training, Benefits of Training, and Support for Training are the independent variables and POBs are the dependent variables. Based on the research model, hypotheses and sub-hypotheses of the research are structured as:

\section{$\boldsymbol{H}_{1}$ : Motivation for training has a significantly positive effect on prosocial organizational behavior.}

- $\mathbf{H}_{1 a}$ : Motivation for training has a significantly positive effect on prosocial organizational behavior.

- $\mathbf{H}_{1 \mathrm{~b}}$ : Motivation for training has a significantly positive effect on role-prescribed prosocial behavior.

- $H_{1 c}$ : Motivation for training has a significantly positive effect on prosocial individual behavior.

$\mathrm{H}_{2}$ : Benefits of training have a significantly positive effect on prosocial organizational behavior.

- $\mathbf{H}_{2 \mathbf{a}}$ : Benefits of training have a significantly positive effect on prosocial organizational behavior.

- $\mathbf{H}_{2 b}$ : Benefits of training have a significantly positive effect on role-prescribed prosocial behavior.

- $\mathbf{H}_{2 c}$ : Benefits of training have a significantly positive effect on prosocial individual behavior.

$\boldsymbol{H}_{3}$ : Support for training has a significantly positive effect on prosocial organizational behavior.

- $\mathbf{H}_{3 \mathbf{a}}$ : Support for training has a significantly positive effect on prosocial organizational behavior.

- $\mathbf{H}_{3 \mathrm{~b}}$ : Support for training has a significantly positive effect on role-prescribed prosocial behavior.

- $\mathbf{H}_{3 \mathbf{c}}$ : Support for training has a significantly positive effect on prosocial individual behavior.

\subsection{Sample}

The target population for this research is the employees who are working in Arabian Gulf Oil Company (AGOCO), the first and the largest Libyan nationalized oil company. Being one of the major oil and gas companies of the World, AGOCO continues to provide training opportunities to its employees both locally and overseas (inside and outside Libya) despite the security problems and economic crisis in Libya. There were approximately 6200 employees at AGOCO at the time of the study. It is difficult in this study to get the opinion of every employee in this oil company. Therefore, Krejcie and Morgan's (1970) table for determining the sample size of a known population was utilized for determining sample size in this study. According to this, the sample size should be at least 361 . Therefore, 400 questionnaires were distributed among employees. Out of them, 382 questionnaires were found adequate and appropriate enough to be included in the study after excluding 18 questionnaires, as they were not fully completed by participants. So, the size of the sample is determined as 382, which was more than the required number (Krejcie \& Morgan, 1970).

Participants of this study were categorized into five groups according to their gender, age group, education level, status, and seniority in AGOCO. The largest group of the participants were males $(81.9 \% ; 313$ male). The majority of the participants were between $31-50$ years old (65.2\%; 249 participants). The highest percentage of the education level was $29.6 \%$, which represents the secondary or high school. This is followed by $29.1 \%$ with higher institute diploma and $20.7 \%$ with vocational institute diploma. Others were at the university level. Besides, it should be emphasized that work circumstances or conditions in the oil sector require vocational certificates. On the other hand, the majority of the participants have seniority in the company between 1-30 years (93\%; 355 participants). Thus, it may be thought that participants of the study have good knowledge about their company and its functions.

\subsection{Data Gathering}

Data of the research was gathered by questionnaire and the questionnaires were distributed and received with the support of the director of the Training Department at AGOCO by taking approval from the company. The data was collected between March-May 2018. A cover letter accompanied each questionnaire to inform the participants about the aims of the research. In the questionnaire, for gathering the data, "motivation for training scale", "benefits of training scale", "support for training scale" and "prosocial 
organizational behaviors scale" were utilized. Besides, confirmatory factor analysis was performed for each scale to test the structural validity and Cronbach alpha coefficient value was examined for testing the internal consistency (reliability) of the scales.

Motivation for training scale: Motivation for training is clearly accepted in the literature as the main part of a training programme. In this study, the "motivation for training scale" developed by Noe and Schmitt (1986) was used. It is a five-point Likert-type scale ( $1=$ Strongly Disagree and $5=$ Strongly Agree). Bulut and Çulha (2010) used this scale in their research with nine items as one dimension for determining the relationship between employee training and affective commitment. Thus, this scale is used in this study by taking into consideration the research of Bulut and Çulha (2010). Items of the scale are used for measuring the motivation of employees of an organization to employee training programmes that are planned and implemented for their development.

Table 1. Confirmatory Factor Analysis of Motivation for Training Scale

\begin{tabular}{ccc}
\hline Fit Measures & Acceptable Fit Values & Model Fit Values \\
\hline RMSEA & $0.05<\mathrm{RMSEA}<0.10$ & 0.054 \\
\hline $\mathrm{CMIN} / \mathrm{DF}$ & $2 \mathrm{df} \leq \mathrm{CMIN} / \mathrm{DF} \leq 3 \mathrm{df}$ & 2.097 \\
\hline $\mathrm{GFI}$ & $0.90<\mathrm{GFI}<0.95$ & 0.971 \\
\hline $\mathrm{NFI}$ & $0.90<\mathrm{NFI}<0.95$ & 0.943 \\
\hline $\mathrm{CFI}$ & $0.90<\mathrm{CFI}<0.95$ & 0.969 \\
\hline
\end{tabular}

Findings related to confirmatory factor analysis of the motivation for training scale demonstrated that the model has acceptable fit values. Fit measures calculated as RMSEA value 0.054; CMIN/DF value 2.097; GFI value 0.971 ; NFI value 0.943 and CFI value 0.969 . These findings revealed that the motivation for training scale has confirmed its one-dimensional factor structure and the scale is in good fit with the original scale. The internal consistency analysis of the scale was performed due to the Cronbach alpha coefficient and the value was measured as $74.2 \%$. This value is above the acceptability limit of $70 \%$ for reliability. Therefore, findings indicate that the motivation for training scale has a good degree of internal consistency.

Benefits of training scale: Benefits of training are clearly accepted in the literature as the main part of a training programme. In this study, the "benefits of training scale" developed by Noe and Wilk (1993) was used. The scale consists of three-dimension (personal-related benefits, career-related benefits, and jobrelated benefits) and it is a five-point Likert-type scale ( $1=$ Strongly Disagree and $5=$ Strongly Agree). Bulut and Çulha (2010) used this scale in their research with twelve items as three-dimension for determining the relationship between employee training and affective commitment. Thus, this scale is used in this study by taking into consideration the research of Bulut and Çulha (2010). Items of the scale are used for measuring the benefits of employee training programmes for employees by emphasizing different benefits obtained from an employee training programme.

Table 2. Confirmatory Factor Analysis of Benefits of Training Scale

\begin{tabular}{ccc}
\hline Fit Measures & Acceptable Fit Values & Model Fit Values \\
\hline RMSEA & $0.05<$ RMSEA $<0.10$ & 0.058 \\
\hline CMIN/DF & $2 \mathrm{df} \leq \mathrm{CMIN} / \mathrm{DF} \leq 3 \mathrm{df}$ & 2.295 \\
\hline $\mathrm{GFI}$ & $0.90<\mathrm{GFI}<0.95$ & 0.953 \\
\hline $\mathrm{NFI}$ & $0.90<\mathrm{NFI}<0.95$ & 0.921 \\
\hline $\mathrm{CFI}$ & $0.90<\mathrm{CFI}<0.95$ & 0.953 \\
\hline
\end{tabular}


Findings related to confirmatory factor analysis of the benefits of training scale demonstrated that the model has acceptable fit values. Fit measures calculated as RMSEA value 0.058; CMIN/DF value 2.295; GFI value 0.953 ; NFI value 0.921 and CFI value 0.953 . These findings revealed that the benefits of training scale has confirmed its three-dimensional factor structure and the scale is in good fit with the original scale. Additionally, the scale utilized in this study is one dimension in the context of the main purpose of the study. The internal consistency analysis of the scale was performed due to the Cronbach alpha coefficient and the value was measured as $77 \%$. This value is above the acceptability limit of $70 \%$ for reliability. Therefore, findings indicate that the benefits of training scale has a good degree of internal consistency.

Support for training scale: Support for training is clearly accepted in the literature as the main part of a training programme. In this study, the "support for training scale" adopted by Bulut and Çulha (2010) from the studies of Noe and Wilk (1993) and Bartlett (2001) was used. It is a five-point Likert-type scale (1= Strongly Disagree and $5=$ Strongly Agree). Bulut and Çulha (2010) used this scale in their research with six items as one dimension for determining the relationship between employee training and affective commitment. Thus, this scale is used in this study by taking into consideration the research of Bulut and Çulha (2010). Items of the scale used for measuring support for employees to attend employee training programmes to gain advantages of training programmes in all aspects of their job.

Table 3. Confirmatory Factor Analysis of Support for Training Scale

\begin{tabular}{ccc}
\hline Fit Measures & Acceptable Fit Values & Model Fit Values \\
\hline $\mathrm{RMSEA}$ & $0.05<\mathrm{RMSEA}<0.10$ & 0.025 \\
\hline $\mathrm{CMIN} / \mathrm{DF}$ & $2 \mathrm{df} \leq \mathrm{CMIN} / \mathrm{DF} \leq 3 \mathrm{df}$ & 1.233 \\
\hline $\mathrm{GFI}$ & $0.90<\mathrm{GFI}<0.95$ & 0.992 \\
\hline $\mathrm{NFI}$ & $0.90<\mathrm{NFI}<0.95$ & 0.985 \\
\hline $\mathrm{CFI}$ & $0.90<\mathrm{CFI}<0.95$ & 0.997 \\
\hline
\end{tabular}

Findings related to confirmatory factor analysis of support for training scale demonstrated that the model has acceptable fit values. Fit measures calculated as RMSEA value 0.025; CMIN/DF value 1.233; GFI value 0.992; NFI value 0.985 and CFI value 0.997 . These findings revealed that the benefits of training scale has confirmed its one-dimensional factor structure and the scale is in good fit with the original scale. The internal consistency analysis of the scale was performed due to the Cronbach alpha coefficient and the value was measured as $78.4 \%$. This value is well above the acceptability limit of $70 \%$ for reliability. Therefore, findings indicate that the support for training scale has a good degree of internal consistency.

Prosocial organizational behavior scale: POBs of employees were measured by the "prosocial organizational behaviors scale" developed by McNeely and Meglino (1994). This scale is accepted in the literature as a three-dimensional five-point Likert-type scale ( $1=$ Strongly Disagree and $5=$ Strongly Agree). The scale consists of 20 items, 7 of which measures prosocial organizational behavior, 7 of which measures role-prescribed prosocial behavior, and 6 of which measures prosocial individual behavior. Items of the scale used for measuring prosocial organizational behavior, role-prescribed prosocial behavior, and prosocial individual behavior of employees into their organization.

Table 4. Confirmatory Factor Analysis of Prosocial Organizational Behavior Scale

\begin{tabular}{ccc}
\hline Fit Measures & Acceptable Fit Values & Model Fit Values \\
\hline RMSEA & $0.05<$ RMSEA $<0.10$ & 0.035 \\
\hline $\mathrm{CMIN} / \mathrm{DF}$ & $2 \mathrm{df} \leq \mathrm{CMIN} / \mathrm{DF} \leq 3 \mathrm{df}$ & 1.468 \\
\hline $\mathrm{GFI}$ & $0.90<\mathrm{GFI}<0.95$ & 0.949 \\
\hline $\mathrm{NFI}$ & $0.90<\mathrm{NFI}<0.95$ & 0.905 \\
\hline $\mathrm{CFI}$ & $0.90<\mathrm{CFI}<0.95$ & 0.967 \\
\hline
\end{tabular}


Findings related to confirmatory factor analysis of the prosocial organizational behaviors scale demonstrated that the model has acceptable fit values. Fit measures calculated as RMSEA value 0.035; CMIN/DF value 1.468; GFI value 0.949 ; NFI value 0.905 and CFI value 0.967 . These findings revealed that the prosocial organizational behaviors scale has confirmed its three-dimensional factor structure and the scale is in good fit with the original scale. The internal consistency analysis of the scale was performed due to the Cronbach alpha coefficient and the value was measured as $86.1 \%$ for the general of the scale, $76.5 \%$ for prosocial organizational behavior, $\mathbf{7 5 . 9 \%}$ for role-prescribed prosocial behavior, and 71.1 for prosocial individual behavior. These values are well above the acceptability limit of $70 \%$ for reliability. Therefore, findings indicate that the prosocial organizational behaviors scale and its dimensions have a good degree of internal consistency.

\section{Findings}

The correlation analysis was performed to measure the relationships between variables of the research. Findings of correlation analysis between motivation for training, benefits of training, support for training, and $\mathrm{POB}$ (prosocial organizational behavior, role-prescribed prosocial behavior, and prosocial individual behavior) were presented in Table 5.

Table 5. Findings of Correlation Analysis Between Variables

\begin{tabular}{|c|c|c|c|c|c|c|c|c|c|c|}
\hline \multicolumn{2}{|c|}{ Variables } & $\mathbf{x}$ & SD & 1 & 2 & 3 & 4 & 5 & 6 & 7 \\
\hline 1 & Prosocial Organizational Behavior & 4.05 & 0.357 & 1 & & & & & & \\
\hline 2 & Prossocial org. behavior & 4.11 & 0.445 & $0.853^{* *}$ & 1 & & & & & \\
\hline 3 & Role-prescribed prosocial bhv. & 4.19 & 0.431 & $0.859^{* *}$ & $0.635^{* *}$ & 1 & & & & \\
\hline 4 & Prosocial individual behavior & 3.82 & 0.435 & $0.728^{* *}$ & $0.408^{* *}$ & $0.439^{* *}$ & 1 & & & \\
\hline 5 & Motivation for training & 4.06 & 0.394 & $0.433^{* *}$ & $0.372^{* *}$ & $0.441^{* *}$ & $0.234^{* *}$ & 1 & & \\
\hline 6 & Benefits of training & 3.80 & 0.547 & $0.334^{* *}$ & $0.262^{* *}$ & $0.264^{* *}$ & $0.296^{* *}$ & $0.407^{* *}$ & 1 & \\
\hline 7 & Support for training & 3.38 & 0.682 & $0.384^{* *}$ & $0.274^{* *}$ & $0.344^{* *}$ & $0.327^{* *}$ & $0.213^{* *}$ & $0.487^{* *}$ & 1 \\
\hline
\end{tabular}

It can be seen in Table 5 that motivation for training has a statistically significant and positive correlation with POB $\left(r=0.433^{* *}\right)$ and its dimensions as prosocial organizational behavior $\left(r=0.372^{* *}\right)$, roleprescribed prosocial behavior $\left(r=0.441^{* *}\right)$ and prosocial individual behavior $\left(r=0.234^{* *}\right)$. Benefits of training also have a statistically significant and positive correlation with POB $\left(r=0.334^{* *}\right)$ and its dimensions as prosocial organizational behavior $\left(r=0.262^{* *}\right)$, role-prescribed prosocial behavior $\left(r=0.264^{* *}\right)$ and prosocial individual behavior $\left(r=0.296^{* *}\right)$. Finally, support for training also has a statistically significant and positive correlation with POB $\left(r=0.384^{* *}\right)$ and its dimensions as prosocial organizational behavior $\left(r=0.274^{* *}\right)$, roleprescribed prosocial behavior $\left(r=0.344^{* *}\right)$ and prosocial individual behavior $\left(r=0.327^{* *}\right)$. Findings of correlation analysis revealed that $\mathrm{POB}$ and all of its dimensions are positively correlated with motivation for training, benefits of training, and support for training. Therefore, these findings indicated that the positive increase in the $\mathrm{POB}$ and its dimensions are probably explained by the positive increase in motivation for training, benefits of training, and support for training.

The main objective of this study is to examine whether employee training (motivation for training, benefits of training, and support for training) has a significant and positive effect on prosocial organizational behaviors. In this context, regression analysis was utilized to test the hypotheses of the study. 
Table 6. Findings of Regression Analysis for the Relationship Between Motivation for Training and Organizational Prosocial Behavior

\begin{tabular}{lcccccc}
\hline Independent variable: Motivation for Training & & & & & \\
\hline Dependent variables & Adj. $\mathbf{R}^{\mathbf{2}}$ & $\mathbf{F}$ & $\boldsymbol{\beta}$ & $\mathbf{t}$ & $\mathbf{p}$ & DW \\
\hline Prosocial Organizational Behavior & 0.186 & $\begin{array}{c}87.787 \\
\left(0.000^{*}\right)\end{array}$ & 0.433 & 9.369 & $0.000^{*}$ & 1.784 \\
\hline Prosocial organizational behavior & 0.136 & $\begin{array}{c}60.979 \\
\left(0.000^{*}\right)\end{array}$ & 0.372 & 7.809 & $0.000^{*}$ & 1.910 \\
\hline Role-prescribed prosocial behavior & 0.192 & $\begin{array}{c}91.580 \\
\left(0.000^{*}\right)\end{array}$ & 0.441 & 9.570 & $0.000^{*}$ & 1.761 \\
\hline Prosocial individual behavior & 0.052 & $\begin{array}{c}21.919 \\
\left(0.000^{*}\right)\end{array}$ & 0.234 & 4.682 & $0.000^{*}$ & 1.932 \\
\hline
\end{tabular}

${ }^{*} p<0.01 ; * * p<0.05$

As presented in Table 6, findings of regression analysis between the independent variable (motivation for training) and dependent variables (POB and its dimensions) show that motivation for training explains the $18.6 \%\left(R^{2}=0.186\right)$ of the variance of prosocial organizational behavior. Similarly, motivation for training explains the $13.6 \%\left(R^{2}=0.136\right)$ of the variance of prosocial organizational behavior, the $19.2 \%$ $\left(R^{2}=0.192\right)$ of the variance of role-prescribed prosocial behavior, and the $5.2 \%\left(R^{2}=0.052\right)$ of the variance of prosocial individual behavior. Durbin-Watson test value found between 1.5-2.5 and it can be said there is no autocorrelation in residuals of regression analysis. About the main hypothesis based on motivation for training, it is obvious that motivation for training has a significantly positive effect on $\mathrm{POB}$ and its dimensions. In this context, the first main hypothesis $\left(H_{1}\right)$ and sub-hypotheses of this hypothesis $\left(H_{1 a}, H_{1 b}\right.$, and $\left.H_{1 c}\right)$ are supported.

Table 7. Findings of Regression Analysis for the Relationship Between Benefits of Training and Organizational Prosocial Behavior

\begin{tabular}{lccccccc}
\hline Independent variable: Benefits of Training & & & & & & \\
\hline Dependent variables & $\mathbf{A d j .} \mathbf{R}^{\mathbf{2}}$ & $\mathbf{F}$ & $\boldsymbol{\beta}$ & $\mathbf{t}$ & $\mathbf{p}$ & $\mathbf{D W}$ \\
\hline Prosocial Organizational Behavior & 0.109 & $\begin{array}{c}47.620 \\
\left(0.000^{*}\right)\end{array}$ & 0.334 & 6.901 & $0.000^{*}$ & 1.812 \\
\hline Prosocial organizational behavior & 0.066 & $\begin{array}{c}28.038 \\
\left.(0.00)^{*}\right)\end{array}$ & 0.262 & 5.295 & $0.000^{*}$ & 1.901 \\
\hline Role-prescribed prosocial behavior & 0.067 & $\begin{array}{c}28.431 \\
\left(0.000^{*}\right)\end{array}$ & 0.264 & 5.332 & $0.000^{*}$ & 1.842 \\
\hline Prosocial individual behavior & 0.085 & $\begin{array}{c}36.544 \\
\left(0.000^{*}\right)\end{array}$ & 0.296 & 6.045 & $0.000^{*}$ & 1.859 \\
\hline
\end{tabular}

${ }^{*} p<0.01 ; * * p<0.05$

As presented in Table 7., findings of regression analysis between independent variables (benefits of training) and dependent variables (POB and its dimensions) show that benefits of training explain the $10.9 \%$ $\left(R^{2}=0.109\right)$ of the variance of prosocial organizational behavior. Similarly, the benefits of training explain the $6.6 \%\left(R^{2}=0.066\right)$ of the variance of prosocial organizational behavior, the $6.7 \%\left(R^{2}=0.067\right)$ of the variance of role-prescribed prosocial behavior, and the $8.5 \%\left(R^{2}=0.085\right)$ of the variance of prosocial individual behavior. Durbin-Watson test value found between 1.5-2.5 and it can be said there is no autocorrelation in residuals of regression analysis. About the second main hypothesis based on the benefits of training, it is obvious that the benefits of training have a significantly positive effect on $\mathrm{POB}$ and its dimensions. In this context, the second main hypothesis $\left(\mathrm{H}_{2}\right)$ and sub-hypotheses of this hypothesis $\left(\mathrm{H}_{2 a}, \mathrm{H}_{2 b}\right.$, and $\left.\mathrm{H}_{2 c}\right)$ are supported. 
Table 8. Findings of Regression Analysis for the Relationship Between Support for Training and Organizational Prosocial Behavior

\begin{tabular}{|c|c|c|c|c|c|c|}
\hline \multicolumn{7}{|c|}{ Independent variable: Support for Training } \\
\hline Dependent variables & Adj. $R^{2}$ & $\mathbf{F}$ & $\boldsymbol{\beta}$ & $\mathbf{t}$ & $\mathbf{p}$ & DW \\
\hline Prosocial Organizational Behavior & 0.145 & $\begin{array}{c}65.657 \\
\left(0.000^{*}\right)\end{array}$ & 0.384 & 8.103 & $0.000 *$ & 1.940 \\
\hline Prosocial organizational behavior & 0.073 & $\begin{array}{c}30.818 \\
\left(0.000^{*}\right)\end{array}$ & 0.274 & 5.551 & $0.000 *$ & 1.982 \\
\hline Role-prescribed prosocial behavior & 0.116 & $\begin{array}{c}50.850 \\
\left(0.000^{*}\right)\end{array}$ & 0.344 & 7.131 & $0.000 *$ & 1.856 \\
\hline Prosocial individual behavior & 0.105 & $\begin{array}{c}45.614 \\
(0.000 *)\end{array}$ & 0.327 & 6.754 & $0.000 *$ & 1.952 \\
\hline
\end{tabular}

${ }^{*} \mathrm{p}<0.01 ; * * \mathrm{p}<0.05$

As presented in Table 8., findings of regression analysis between independent variables (support for training) and dependent variables (POB and its dimensions) show that support for training explains the $14.5 \%$ $\left(R^{2}=0.145\right)$ of the variance of prosocial organizational behavior. Similarly, support for training explains the $7.3 \%\left(R^{2}=0.073\right)$ of the variance of prosocial organizational behavior, the $11.6 \%\left(R^{2}=0.116\right)$ of the variance of role-prescribed prosocial behavior, and the $10.5 \%\left(R^{2}=0.105\right)$ of the variance of prosocial individual behavior. Durbin-Watson test value found between 1.5-2.5 and it can be said there is no autocorrelation in residuals of regression analysis. About the third main hypothesis based on support for training, it is obvious that support for training has a significantly positive effect on $\mathrm{POB}$ and its dimensions. In this context, the third main hypothesis $\left(\mathrm{H}_{3}\right)$ and sub-hypotheses of this hypothesis $\left(\mathrm{H}_{3 a}, \mathrm{H}_{3 b}\right.$, and $\left.\mathrm{H}_{3 c}\right)$ are supported.

\section{Conclusion}

The fundamental objective of this study is to investigate the effect of employee training programmes (motivation for training, benefits of training, and support for training) on the POBs of employees in the context of the Libyan oil sector. Findings of regression analyses performed for testing the hypotheses of the study demonstrated that the positive increase in the POBs (prosocial organizational behavior, role-prescribed prosocial behavior, and prosocial individual behavior) is explained by the positive increase in motivation for training, benefits of training, and support for training. Thus, all the hypotheses of the study were supported.

It has been clearly found in the literature that employee training programmes are important for encouraging prosocial behaviors as they increase the intent of employees to promote the welfare of another employee, group, or organization (Brief \& Motowidlo, 1986). It has also been revealed in the literature that motivation for training, benefits of training, and support for training encourages prosocial behaviors (Chebat, Babin \& Kollias, 2002). As explained above, findings of this study show that motivation for training, benefits of training, and support for training were significantly and positively linked with POBs, and findings of this study were compatible with the findings in the literature. It can be said that motivation for training, benefits of training, and support for training are critical for promoting POBs because in that case, employees start feeling helpful for colleagues and develop a strong desire to do something good for their welfare. The current findings showed that employee training programmes play an important role in enhancing POBs by boosting the intention of organizational members to promote the welfare of other employees, workgroups, or even organizations. Specifically, the current findings showed that motivation for training, benefits of training, and support for training play a role in creating helpful behaviors of employees and work-group aimed at endorsing the welfare of others in the organizations. Brief and Motowidlo (1986) have a remarkable contribution to the literature and what we understand about this topic today. They believed that organizations should encourage and even promote prosocial organizational behaviors. These helpful behaviors not only improve the welfare of others but also improve customer services, organizational loyalty, job satisfaction, and overall well-being of the organization (Chebat et al., 2002). 
This study will prove to be a remarkable contribution to the literature on employee training programmes and prosocial organizational behaviors. The important aspect of the study is the enhancement of prosocial behaviors because in this case, employees have an intention to promote the welfare of others, which results in improving employees' performance as well. Specifically, studies of POB and the relationship of this variable to other organizational behavior variables may develop the understanding of prosocial organizational behavior. Thus relevant literature will gain some consensus to its benefit to the organization. This study can serve as the basis for additional researches in all Libyan sectors. This study considered training as a potential antecedent of prosocial organizational behaviors. Other variables should also be explored. Hence, the undertaken study has the potential to underpin more efforts related to employee training programmes and prosocial organizational behaviors.

\section{Declarations and Disclosures}

Ethical Responsibilities of Authors: The authors of this article confirm that their work complies with the principles of research and publication ethics.

Conflicts of Interest: No potential conflict of interest was reported by the authors.

Funding: The authors received no financial support for the preparation and/or publication of this article.

Author Contributions: The authors confirm contribution to the article as follows: Conceptualization and design, H. R. H. Elkhdr and A. Kanbur; data collection, H. R. H. Elkhdr; analysis of data and interpretation of results, H. R. H. Elkhdr and A. Kanbur; writing the first draft of the manuscript, H. R. H. Elkhdr and A. Kanbur; review and editing, H. R. H. Elkhdr and A. Kanbur. The manuscript/article was read and approved by all the authors, and all authors accepted responsibility for their article.

Plagiarism Checking: This article was screened for potential plagiarism using a plagiarism screening program.

(*) Additional Disclosure: This study is derived from the PhD thesis of Hassan R. H. Elkhdr, "Exploring Employee Training Programmes for Organizational Commitment and Prosocial Organizational Behavior", which was prepared under the consultancy of Assoc. Prof. Aysun Kanbur.

\section{References}

Armstrong, M. (1999). A handbook of human resource management practice. London: Kogan Page.

Armstrong, M., \& Taylor, S. (2014). Armstrong's handbook of human resource management practice. London: Kogan Page.

Barney, J. B. (2001). Resource-based theories of competitive advantage: A ten-year retrospective on the resource-based view. Journal of Management, 27(6), 643-650.

Bartlett, K. R. (2001). The relationship between training and organizational commitment: A study in the health care field. Human Resource Development Quarterly, 12(4), 335-361.

Bateman, T. S., \& Organ, D. W. (1983). Job satisfaction and the good soldier: The relationship between affect and employee "citizenship". The Academy of Management Journal, 26(4), 587-595.

Bature, N., Friday, O., \& Mustapha, A. (2013). Manpower training and development: A tool for higher productivity in Zenith Bank Plc, Maitama Branch, Abuja. European Journal of Business and Management, 5(28), 1-9.

Bolino, M. C., \& Grant, A. M. (2016). The bright side of being prosocial at work, and the dark side, too: The Academy of Management Annals, 10(1), 599-670.

Booth, J. E., Park, K. W., \& Glomb, T. M. (2009). Employer-Supported volunteering benefits: Gift exchange among employers, employees, and volunteer organizations. Human Resource Management, 48(2), 227-249.

Boundenghan, M., Desrumaux, P., Leoni, V., \& Nicolas, C. V. (2012). Predicting prosocial behavior in the workplace: Links with organizational justice, commitment, affectivity, and personality. Revue Internationale de Psychologie Sociale, 25(3), 13-38.

Bramley, P. (1991). Evaluating training effectiveness: Translating theory into practice. Sydney: McGraw-Hill Book Company. 
Brief, A. P., \& Motowidlo, S. J. (1986). Prosocial organizational behaviors. Academy of Management Review, 11(4), 710725.

Bulut, C., \& Çulha, O. (2010). The effects of organizational training on organizational commitment. International Journal of Training and Development, 14(4), 309-322.

Bülbül, A. (2014). Social work design and prosocial organizational behaviors. Universal Journal of Psychology, 2(2), 4758.

Casciaro, T., \& Lobo, M. S. (2008). When competence is irrelevant: The role of interpersonal affect in task-related ties. Administrative Science Quarterly, 53(4), 655-684.

Chebat, J. C., Babin, B., \& Kollias, P. (2002). What makes contact employees perform? Reactions to employee perceptions of managerial practices. International Journal of Bank Marketing, 20(7), 325-332.

Cicekli, E., \& Kabasakal, H. (2017). The opportunity model of organizational commitment: Evidence from white-collar employees in Turkey. International Journal of Manpower, 38(2), 259-273.

Dovidio, J. F., \& Penner, L. A. (2001). Helping and altruism. In G. J. O. Fletcher \& M. S. Clark (Eds.), Blackwell handbook of social psychology: Interpersonal processes (pp. 162-195). Padstow: Blackwell Publishing.

Egan, M. B., Raats, M. M., Grubb, S. M., Eves, A., Lumbers, M. L., Dean, M. S., \& Adams, M. R. (2007). A review of food safety and food hygiene training studies in the commercial sector. Food Control, 18(10), 1180-1190.

Elliott, G., Kao, S., \& Grant, A. M. (2004). Mattering: Empirical validation of a social-psychological concept. Self and Identity, 3(4), 339-354.

Fatkin, J. M. (2015). 'Pro'social media: Using key social psychological theories to increase prosocial engagement on social media sites. (Doctoral Dissertation). Heriot-Watt University, School of Life Sciences, Philosophy in Applied Psychology, Edinburgh.

Frenkel, S. J., \& Bednall, T. (2016). How training and promotion opportunities, career expectations, and two dimensions of organizational justice explain discretionary work effort. Human Performance, 29(1), 16-32.

George, J. M., \& Brief, A. P. (1992). Feeling good-doing good: A conceptual analysis of the mood at work-organizational spontaneity relationship. Psychological Bulletin, 112(2), 310-329.

Gomez-Mejia, L. R., Balkin, D. B., \& Cardy, R. L. (2012). Managing human resources. New Jersey: Pearson.

Grant, A. M. (2012). Leading with meaning: Beneficiary contact, prosocial impact, and the performance effects of transformational leadership. Academy of Management Journal, 55(2), 458-476.

Hazzi, O. A., \& Maldaon, I. S. (2012). Prosocial organizational behaviors: The lifeline of organizations. European Journal of Economics, Finance and Administrative Sciences, (54), 106-114.

Hendry, C. (2012). Human resource management. NY: Routledge.

Huselid, M. A. (1995). The impact of human resource management practices on turnover, productivity, and corporate financial performance. Academy of Management Journal, 38(3), 635-672.

Jehanzeb, K., \& Bashir, N. A. (2013). Training and development program and its benefits to employee and organization: A conceptual study. European Journal of Business and Management, 5(2), 243-253.

Kaplan, E. M., \& Cowen, E. L. (1981). Interpersonal Helping behavior of industrial foremen. Journal of Applied Psychology, $66(5), 633-638$.

Katz, D. (1964). The motivational basis of organizational behavior. Behavioral Science, 9(2), 131-146.

Kim, E., \& Glomb, T. M. (2010). Get smarty pants: Cognitive ability, personality, and victimization. Journal of Applied Psychology, 95(5), 889-901.

Krejcie, R. V., \& Morgan, D. W. (1970). Determining sample size for research activities. Educational and Psychological Measurement, 30, 607-610.

Lee, H. J. (2001). Willingness and capacity: The determinants of prosocial organizational behaviour among nurses in the UK. The International Journal of Human Resource Management, 12(6), 1029-1048.

Lee, S. A., \& Liang, Y. (2015). Reciprocity in computer - human interaction: Source based, norm-based, and affect-based explanations. Cyberpsychology, Behavior, and Social Networking, 18(4), 234-240.

Lopez-Perez, R. (2009). Followers and leaders: Reciprocity, social norms and group behavior. The Journal of SocioEconomics, 38, 557-567.

McDougall, W. (1908). Social Psychology. London: Metheun. 
McGrath, C. A., Vance, C. M., \& Gray, E. R. (2003). With a little help from their friends: Exploring the advice networks of software entrepreneurs. Creativity and Innovation Management, 12(1), 2-10.

McNeely, B. L., \& Meglino, B. M. (1994). The role of dispositional and situational antecedents in prosocial organizational behavior: An examination of the intended beneficiaries of prosocial behavior. Journal of Applied Psychology, 79(6), 836-844.

Molla Belay, H. (2016). Employees training practices in pharmaceticals fund and supply agency. (Doctoral dissertation). St. Mary's University Business Administration, Ethiopia.

Nikandrou, I., Brinia, V., \& Bereri, E. (2009). Trainee perceptions of training transfer: An empirical analysis. Journal of European Industrial Training, 33(3), 255-270.

Noe, R. A. (2010). Employee training and development. New York: McGraw-Hill Irwin.

Noe, R. A. \& Schmitt, N. (1986). The influence of trainee attitudes on training effectiveness: Test of a model. Personnel Psychology, 39(3), 497-523.

Noe, R. A., \& Wilk, S. L. (1993). Investigation of the factors that influence employees' participation in development activities. Journal of Applied Psychology, 78(2), 291-302.

O’Reilly, C., \& Chatman, J. (1986). Organizational commitment and psychological attachment: The effects of compliance, Identification, and internalization on prosocial behavior. Journal of Applied Psychology, 71(3), 492-499.

Organ, D. W. (1977). A reappraisal and reinterpretation of the satisfaction-causes-hypothesis. The Academy of Management Review, 2(1), 46-53.

Organ, D. W., \& Konovsky, M. (1989). Cognitive versus affective determinants of organizational citizenship behavior. Journal of Applied Psychology, 74(1), 157-164.

Penner, L. A., Dovidio, J. F., Piliavin, J. A., \& Schroeder, D. A. (2005). Prosocial behavior: Multilevel perspectives. Annual Review of Psychology, 56(1), 365-392.

Piliavin, J. A., \& Charng, H. W. (1990). Altruism : A review of recent theory and research. Annual Review of Sociology, 16(1), 27-65.

Rabin, M. (1993). Incorporating fairness into game theory and economics. American Economic Review, 83, 1281-1302.

Reid, M. A., \& Barrington, H. A. (2001). Training intervention: Promoting learning opportunities. London: CIPD.

Salamon, S. D., \& Deutsch, Y. (2006). OCB as a handicap: An evolutionary psychological perspective. Journal of Organizational Behavior, 27(2), 185-199.

Shen, J. (2005). International training and management development: Theory and reality. Journal of Management Development, 24(7), 656-666.

Smith, C. A., Organ, D. W., \& Near, J. P. (1983). Organizational citizenship behavior: Its nature and antecedents. Journal of Applied Psychology, 68(4), 653-663.

Staw, B. M. (1984). Organizational behavior: A review and reformulation of the field's outcome variables. Annual Review of Psychology, 35(1), 627-666.

Tunio, G., Channa, N., \& Pathan, S. K. (2016). Training practices and their effectiveness in non-government organizations of Pakistan. International Research Journal of Arts \& Humanities, 44(44), 191-199.

Werner, J. M. (1994). Dimensions that make a difference: Examining the impact of in-role and extrarole behaviors on supervisory ratings. Journal of Applied Psychology, 79(1), 98-107.

Zellars, K. L., Tepper, B. J., \& Duffy, M. K. (2002). Abusive supervision and subordinates' organizational citizenship behavior. Journal of Applied Psychology, 87(6), 1068-1076. 